\title{
Cooperative Catalysis by Indium and Palladium for the Allyl Cross-Coupling Reactions ${ }^{\dagger}$
}

\author{
Jae-Young Lee and Phil Ho Lee" \\ Department of Chemistry and Institute for Basic Science, Kangwon National University, Chnchon 200-701, Korea \\ "E-mail: phlee@kangwon.ackr. \\ Received Mav 31, 2007
}

Key Words : Catalysis, Cross-coupling, Indium, Palladium, Manganese

Indium has emerged as useful metals in organic synthesis because of their intriguing chemical properties. ${ }^{1}$ On the basis of these properties, a range of indium-mediated organic reactions have been found to be useful for organic reactions. ${ }^{2}$ Generally, indium has been used in a stoichiometric amount in almost all of organic reactions. Accordingly, if catalytic amounts of indium can be used in organic reactions, its usefulness and versatility should remarkably be increased. Recently, aqueous allylation reactions using a catalytic amount of $\mathrm{InCl}_{3}{ }^{3}$ and indium-catalyzed allylation reaction were reported. ${ }^{4}$ Despite the recent progress, there is still strong need for various and efficient indium-catalyzed organic reactions. Although the transition-metal catalyzed cross-couplings are one of the most straightforward methods for C-C bond formation," cross-couplings catalyzed by cooperative indium and palladium are to date unknown. ${ }^{6}$ We describe herein cooperative indium and palladium-catalyzed allyl cross-coupling reactions with manganese (Scheme 1).

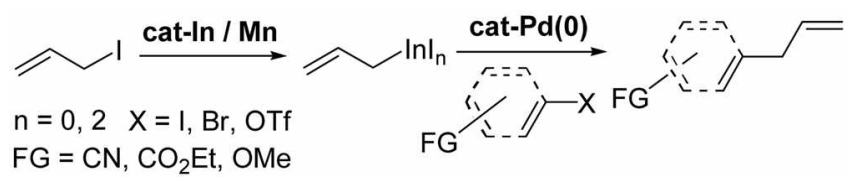

Scheme 1. Cooperative catalysis by indium and palladium for the allyl cross-coupling raaction.

First, the reaction of allylindium generated in situ from indium and ally] iodide with I-halonaphthalene was examined (Table 1). The reaction of 1 (I equiv.) with ally] jodide ( 1.5 equiv.), In $(20 \mathrm{~mol} \%)$ and $\mathrm{Mn}(3$ equiv. $)$ in the presence of $3 \mathrm{~mol} \%$ of $\left(\mathrm{Ph}_{3} \mathrm{P}\right)_{4} \mathrm{Pd}$ and $\mathrm{LiCl}(3$ equiv.) produced $4(20 \%), 5(55 \%)$ and $6(15 \%)$ in DMF at $100^{\circ} \mathrm{C}$ under a nitrogen atmosphere (entry 11 ).<smiles>[X]c1cccc2ccccc12</smiles>

$\mathrm{X}=\mathrm{I}(\mathbf{1}), \mathrm{Br}(\mathbf{2}), \mathrm{Cl}(\mathbf{3})$<smiles>C=CCc1cccc2ccccc12</smiles>
4<smiles>c1ccc2ccccc2c1</smiles>

5

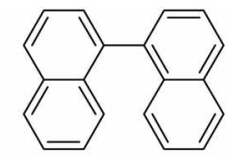

6
The use of $\mathbf{2}$ gave $\mathbf{4}$ and $\mathbf{5}$ in $35 \%$ and $50 \%$ yields, respectively and fomation of 6 was restrained (entry 5). Addition of allyl jodide dropwisely over $4 \mathrm{~h}$ did not effect on

${ }^{7}$ This paper is dedicated to Prolessor Sang Chul Shim on the occasion of his honorable retirement. the reaction. The compound 4 and 5 was obtained in $10 \%$ and $15 \%$ yields, respectively, in dropwise of 2 over $4 \mathrm{~h}$. The compound 3 did not give the desired product. In case of aluminum ( 3 equiv.) and zinc ( 3 equiv.), the compound 4 was produced in $20 \%$ yields (entries 3 and 4 ). Among the ligands $\left(1,2-\left(\mathrm{Ph}_{2} \mathrm{P}\right)\right.$ benzene, $\left(o-\mathrm{Tol}_{3} \mathrm{P}\right.$, Dppe, Dppf, XanPhos, DPPP, DPEphos and (2-Furyl $\left.)_{3} \mathrm{P}\right)$ tested, $\mathrm{Cy}_{3} \mathrm{P}$ gave the best results. DMF was the best solvent among several reaction media. Among the additives $\left(\mathrm{LiX}, \mathrm{K}_{2} \mathrm{CO}_{3}, \mathrm{~K}_{3} \mathrm{PO}_{4}\right.$, $\mathrm{CsF}$ and $n-\mathrm{Bu} \mathrm{wX}_{\mathrm{NX}}$ screened, $\mathrm{LiCl}$ gave the best results. The addition of $\mathrm{InCl}_{3}(5 \mathrm{~mol} \%), \mathrm{InCl}(20 \mathrm{~mol} \%)$ and $\mathrm{InI}(20$ mol\%) did not increase the yield. The use of manganese $(2$ equiv.) gave 4 in $40 \%$ yield (entry 9 ), but the yield decreased to $20 \%$ without manganese (entry 10 ). These results indicate that indium salt $\mathbf{1 3}$ generated through transmetallation was reduced to $\operatorname{In}(0)$ by manganese and subsequently reacted with allyl jodide to produce allylindium. The best results were obtained with 1-bromonaphthalene (1 equiv.) and allyl jodide ( 1.5 equiv.) in the presence of $3 \mathrm{~mol}_{0} \mathrm{Pd}_{2} \mathrm{dba}_{3} \mathrm{CHCl}_{3} /$ $20 \mathrm{~mol} \% \mathrm{Cy}_{3} \mathrm{P}$, indium $(20 \mathrm{~mol} \%$ ), manganese ( 3 equiv.) and $\mathrm{LiCl}$ (3 equiv.) in $\mathrm{DMF}$ at $100^{\circ} \mathrm{C}$ under a nitrogen

Table 1. Reaction optinization ${ }^{2}$

\begin{tabular}{|c|c|c|c|c|c|}
\hline Entry & $\mathrm{X}$ & M & Ligand $^{b}$ & Conversion $(\%)^{c}$ & Yield $(\%)^{6}$ \\
\hline 1 & $\mathrm{Br}$ & Mn & $\mathrm{Cy}_{3} \mathrm{P}$ & $>98$ & $55(20)$ \\
\hline 2 & I & $\mathrm{Mn}$ & $\mathrm{Cy}_{3} \mathrm{P}$ & $>95$ & $15(60)$ \\
\hline 3 & $\mathrm{Br}$ & $\mathrm{Al}$ & $\mathrm{Cy}_{3} \mathrm{P}$ & $>95$ & $20(50)$ \\
\hline 4 & $\mathrm{Br}$ & $7 n$ & $\mathrm{Cy}_{3} \mathrm{P}$ & $>95$ & $20(50)$ \\
\hline $5^{d}$ & $\mathrm{Br}$ & $\mathrm{Mn}$ & - & 80 & $35(50)$ \\
\hline 6 & $\mathrm{Br}$ & Mn & $\mathrm{Ph}_{3} \mathrm{P}$ & 95 & $50(20)$ \\
\hline 7 & $\mathrm{Br}$ & Mn & tert-Bus $\mathrm{P}$ & $>98$ & $10(85)$ \\
\hline $8^{e}$ & $\mathrm{Br}$ & Mn & $\mathrm{Cy}_{3} \mathrm{P}$ & 80 & $43(25)$ \\
\hline $9^{f}$ & $\mathrm{Br}$ & Mn & $\mathrm{Cy}_{3} \mathrm{P}$ & $>98$ & $40(55)$ \\
\hline 10 & $\mathrm{Br}$ & - & $\mathrm{Cy}_{3} \mathrm{P}$ & $>98$ & 20 \\
\hline $11^{\prime \prime}$ & $\mathrm{I}$ & Mn & - & $>95$ & $20(55)(15)$ \\
\hline
\end{tabular}

${ }^{a}$ Reactions were carried out with allyl iodide ( 1.5 equiv), $\ln (20 \mathrm{~mol} \%)$, and $\mathrm{M}$ (3 equiv.) in the presence of $\mathrm{Pd}_{2} \mathrm{dba}_{3} \mathrm{CHCl}_{3}(3 \mathrm{~mol} \%)$ and $\mathrm{LiCl}, 3$ equiv.) in DMF ( $0.2 \mathrm{M}$ ) at $1(0)^{\circ} \mathrm{C}$. for $20 \mathrm{~h}$. 'Ligand ( $20 \mathrm{~mol} \%$ ) was used. "GC yield using $C_{14} \mathrm{I}_{30}$ as an internal standard. Numbers in parenthesis indicate yield 5. "( $\left(\mathrm{Ph}_{3} \mathrm{P}\right)_{4} \mathrm{Pd}(3 \mathrm{~mol} \%)$ was used. "TIIT was used as a solvent. Me (2 equiv.) was used. ${ }^{R} 6$. 
Table 2. Cooperative catalysis by indium and palladium with manganese for the allyl cross-coupling reactions ${ }^{a}$

\begin{tabular}{lll} 
Condition & Yield (\%) \\
\hline
\end{tabular}

"Reactions were carried out in DMF $(0.2 \mathrm{M})$ at 100 ' $\mathrm{C}$ for $20 \mathrm{~h}^{\mathrm{h}}{ }^{\mathrm{A}} \mathrm{A}$ : $\mathrm{Pd}_{2} \mathrm{db}_{3} \mathrm{ClICl}_{3}$ ( $\left.3 \mathrm{~mol} \%\right)^{2}, \mathrm{Cy}_{3} \mathrm{P}(20 \mathrm{~mol} \%), \mathrm{LiCl}$ ( 3 equiv), In $(20$ mol\%), Mn ( 3 equiv.). B: (Biph)PCy $(20 \mathrm{mo} \%$ ). "Tsolated yield. Numbers in parenthesis indicate the GC yield of reduction products using $\mathrm{C}_{14} \mathrm{H}_{30}$ as an internal standard. ${ }^{d} \mathrm{GC}$ yield of 4 . ${ }^{4} \mathrm{In}(30 \mathrm{~mol} \%$ ) was used. ${ }^{\prime} \mathrm{Mn}$ ( 4 equiv.) was used.

atmosphere, producing 4 in $55 \%$ yield (entry 1 ).

Under the optimum conditions, 2-bromonaphthalene and 4-bromobenzonitrile afforded the desired products in $40 \%$ and $46 \%$ yields, respectively (Table 2). In case of triflate of 2-naphthol, 2-allylnaphthalene was produced in $46 \%$ yield with $20 \mathrm{~mol} \%$ (Biph)PCy, (entry 5). Although the use of 30 mol $\%$ of indium increased the product yield in $54 \%$, the use of manganese ( 4 equiv.) decreased yield (44\%) (entries 6 and 7). Triflate of 1-naphthol gave the 4 in $48 \%$ yield (entry 4). Reaction of triflate of ethyl 4-hydroxybenzoate with allylindium afforded the desired product in $52 \%$ yield (entry 8). Allyl cross-coupling product was produced in $71 \%$ yield with indium ( $30 \mathrm{~mol} \%$ ) (entry 9 ). However, triflate of 4hydroxyphenyl methyl ketone yielded allyl alcohol in $70 \%$ yield, indicating that ketone group is more reactive than triflate for allylindndium (eq. 1). Subjecting triflate of 4hydroxyanisole to the optimum conditions gave 4-allylanisole in $42 \%$ yield (entry 10). Vinyl triflate afforded the desired product in $49 \%$ yield (entry 11 ).

A plausible reaction mechanism is shown in Scheme 2 . The initially formed $\sigma$-Pd(II) complex 8 undergoes transmetallation by allylindium 12 to give 9 and indium salt 13 .

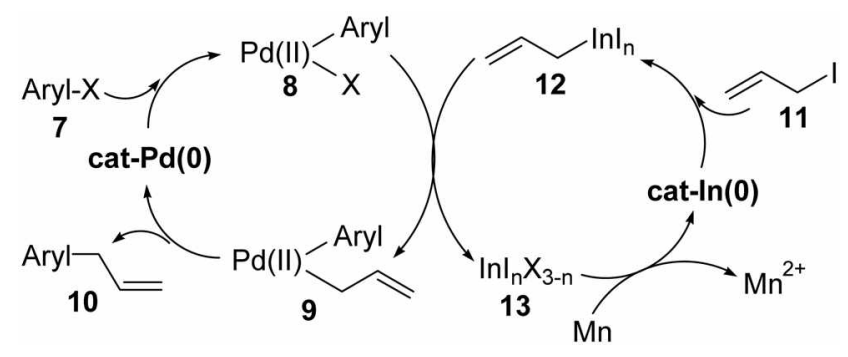

Scheme 2. A plausible reaction inechanisın.

Then, the compound 9 is subjected to reductive elimination to yield ally] cross-coupling products 10. Although we don't know the exact valence of indium in 13, we believe that manganese reduce 13 to regenerate $\operatorname{In}(0)$ because use of manganese increase obviously yield of coupling product. ${ }^{7}$

In summary, cooperative indium and palladium-catalyzed allyl cross-coupling reactions were demonstrated. Allylindium generated in situ from allyl jodide, catalytic amount of indium, and manganese gave allyl cross-coupling products in moderate yields. This is the first example of cooperative catalysis by indium and palladium for crosscoupling reactions.

Acknowledgment. This work was supported by the Korea Science and Engineering Foundation (KOSEF) through the National Research Lab. Program funded by the Ministry of Science and Technology (No. M10600000203-06J000020310), by the CMDS at KAIST and by the Korea Science and Engineering Foundation (KOSEF, R01-2006-00011283-0). The NMR and mass data were obtained from the central instrumental facility in Kangwon National University.

\section{References and Notes}

I. (a) Li, C.-J. Chem. Rev, 1993, 93, 2023. (b) Cintas, P. Synlett 1995, 1087. (c) Li, C.-J. Tetrahedron 1996, 52, 5643. (d) Li, C.-J.; Chan, T.-H. Organic Reactions in Aqueous Media; Wiley: New York, 1997. (e) Li, C.-J.; Chan, T.-H. Tetrahedron 1999, 55, II149. (f) Babu, G; Perumal, P. T. Aldrichimica Acta 2000, 33, 16. (g) Chauhan, K. K.; Frost, C. G. J. Chen. Soc., Perkin Trans. I 2000, 3015. (h) Pae, A. N.; Cho, Y. S. Curr. Org. Chem. 2002, 6 , 715. (i) Podlech, J.; Maier, T. C. Synthesis 2003, 633.

2. (a) Perez, I.; Sestelo, J. P.; Maestro, M. A.; Mourino, A.; Sarandeses, L. A. J. Org. Chem, 1998, 63, 10074, (b) Lee, P. H.; Sung, S.-Y.; Lee, K. Org. Lett. 2001, 3, 3201. (c) Bang, K.; Lee, K.; Park, Y. K.; Lee, P. H. Bull. Korean Chem. Soc. 2002, 23. 1272. (d) Lee. P. H. Bull. Korean Chem. Soc. 2007. 28, 1.

3. Araki, S.; Jin, S.-J.; Idou, Y. Bull. Chem. Soc. Jpn. 1992, 65, 1736.

4. (a) Auge, J.; Lubin-Germain, N.; Thiaw-Woaye, A. Tetrahedron Lett. 1999, 40, 9245. (b) Auge, J.; Lubin-Gemain, N.; Marque, S.; Seghrouchni, L. J. Organoniet. Chem. 2003, 679, 79.

5. (a) Heck, R. F. Pollowitm Reagents in Organic Synthesis; Academic Press: New York, 1985. (b) Tsuji, J. Pallatitm Reagents and Catalyst; Wiley: Chichester, 1995; Chapter 4. (c) Metal-Catalyzed Cross-Conplings Reactions; Diederich, F., Slang, P. J., Eds.; Wiley-VCH: Weinheim, 1998. (d) Negishi, E. Organopalladium Chemistry; Wiley-Interscience: New York, 2002; Vol. I and I.

6. Lee, J. M.; Na. Y; Han. H.; Chang, S. Chent. Soc. Rev. 2004, 33, 302.

7. Standard reduction potential ( $E$ ) of $\mathrm{In}^{111} / \mathrm{Jn}^{0}$ is $-0.3382 \mathrm{~V}, \mathrm{Mn}{ }^{11 /}$ $\mathrm{Mn}^{\prime \prime}$ is $-1.185 \mathrm{~V}$, see: $C R C$ Handbook of Chemistry and Physics, 68th ed.; CRC Press: Boca Ralon, 1987; pp D151-D155. 